\title{
PRÁTICAS DE MANEJO COM LEITÕES LACTENTES: REVISÃO E PERSPECTIVAS VINCULADAS AO BEM-ESTAR ANIMAL
}

\author{
SILVA, Caio Abércio da ${ }^{1}$; \\ DIAS, Cleandro Pazinato ${ }^{2}$; \\ MANTECA, Xavier ${ }^{3}$.
}

Recebido: 16/10/2014

Aceito: 02/04//2015

${ }^{1}$ Departamento de Zootecnia da Universidade Estadual de Londrina, Londrina - PR; ${ }^{2}$ Programa de Pós-
Graduação em Ciência Animal da Universidade Estadual de Londrina, Londrina - PR; ${ }^{3}$ Departamento de Ciência Animal e dos Alimentos da Universidade Autônoma de Barcelona.

\section{RESUMO}

$\mathrm{O}$ s procedimentos de castração de machos, secção da cauda, corte ou desgaste dos dentes e identificação dos leitões são práticas de manejo realizadas largamente logo após o nascimento em granjas comerciais. Apesar das ações terem propósitos bem definidos, resultam em dor aguda e crônica nos leitões, representando um importante problema de bem-estar. A pressão social para o banimento destes procedimentos tem-se intensificado, sendo que vários países vêm restringindo o uso rotineiro destas práticas através de normativas. Atualmente questiona-se muito a forma e a necessidade da manutenção destas práticas, em especial no Brasil, que ainda demanda legislação sobre o tema. Nesta revisão são abordados os impactos destes procedimentos no bem-estar dos suínos e as perspectivas para o setor produtivo brasileiro quanto à adaptação a estas novas tendências. Em síntese, pode-se atribuir que tecnicamente os manejos de corte da cauda e dos dentes mostram-se desnecessários quando os suínos têm suas necessidades básicas atendidas. A castração cirúrgica quando mantida deverá ser efetuada mediante o uso da anestesia e analgesia prolongada, ou então optar-se pela imunocastração. Para todos os manejos visualiza-se a possibilidade de minimização dos impactos negativos inerentes por meio da capacitação constante da mão de obra, uso correto de equipamentos e a manutenção da higiene nestas práticas.

Palavras-chave: Castração cirúrgica. Corte da cauda. Corte dos dentes. Identificação de suínos. Normativas. 


\section{INTRODUÇÃO}

O princípio das cinco liberdades proposto pelo Farm Animal Welfare Council (FAWC, 1992) representa um guia básico para nortear as demandas do bem-estar animal. Para a sociedade o tema corresponde a uma forma prática e efetiva para esclarecimento do significado do bem-estar. O cumprimento das cinco liberdades compreende a garantia de que o animal está livre da fome e da sede, livre do desconforto, da dor, da injúria e das doenças, estando assim em condições plenas para expressar o comportamento normal, isento, portanto, do medo e do distresse, condição básica para uma boa qualidade de vida. Neste contexto, adversamente, algumas práticas de manejo ainda dispensadas aos leitões lactentes cerceiam a magnitude desta proposta, merecendo serem revistas e discutidas.

$\mathrm{Na}$ suinocultura industrial, muitas granjas submetem os leitões lactentes durante os primeiros dias de vida a uma série de procedimentos de manejo, como a castração, o corte da cauda, o corte dos dentes e a identificação (MARCHANT-FORDE et al., 2009). Estas ações reconhecidamente têm um potencial invasivo, resultando inevitavelmente em experiências dolorosas para os leitões. Neste sentido, considerando as orientações do bem-estar, é desejável que estas práticas sejam melhoradas, substituídas por métodos alternativos ou até banidas, gerando benefícios para os animais (AVMA, 2013).

As justificativas para a execução rotineira destas práticas de manejo estão baseadas em hipóteses de interesse econômico e relacionadas à melhora do bem-estar em alguns aspectos. Destacam-se o decréscimo das lesões causadas nos tetos das matrizes lactantes (decorrente do corte dos dentes), a prevenção da caudofagia em animais destinados a engorda (minimizada pelo corte da cauda) e a redução da agressividade dos machos castrados nas fases que sucedem a etapa da creche. Paralelamente, também estão inseridas as vantagens que alguns destes manejos resultam, como por exemplo, a castração dos machos, a qual leva à menor depreciação da carcaça ou, no caso da secção da cauda, à redução de danos em partes das carcaças de animais que sofreram as consequências da caudofagia (PRUNIER et al., 2005).

No entanto, estes procedimentos têm sido cada vez mais criticados, mesmo quando praticados em animais de tenra idade, pois são atingidos tecidos inervados que levam à 
sensação de dor. A presença de células receptoras da dor, nervos em vias nociceptiva, e um cérebro complexo para analisar a entrada de tais sinais, indicam que uma sensação de dor seja percebida pelos animais quando esses tecidos são danificados, um quadro possivelmente semelhante ao que ocorre com o homem. Além disso, as respostas comportamentais dos suínos às intervenções cirúrgicas colaboram com a sustentação deste argumento (SVC, 1997).

Neste sentido, uma série de restrições às práticas da castração, ao corte da cauda e dentes e à identificação dos suínos, que culminam com diferentes graus de mutilação, tem sido tratada há anos pelas normativas de bem-estar animal em vários países. A Europa, por meio da Diretiva 2008/120/EC, exige que somente Médicos Veterinários ou pessoas com curso de formação e experiência na execução destas técnicas, dotadas de meios adequados e em condições higiênicas definidas, poderão realizá-las. Especificamente sobre a redução das pontas dos dentes e o corte da cauda, os mesmos não devem ser executados como rotina, podendo somente ser efetuadas diante de provas de que sua isenção leva, respectivamente, a lesões nos mamilos das porcas, às orelhas dos leitões e à cauda de outros suínos (EUROPEAN COMMISSION, 2008).

De acordo com esta tendência, mais países vêm adotando medidas de restrição similar. Na Austrália, com algumas ressalvas, estas práticas, quando consideradas necessárias, ainda são permitidas, embora seja estimulada a adesão às alternativas que aliviam ou minimizam a dor, sendo proposto evitar tais procedimentos (PISC, 2008). Para a execução destas práticas nas granjas neozelandesas é preciso justificar que sua adoção evita o sofrimento de outras categorias de suínos da unidade, e que previne outros quadros indesejáveis (NAWAC, 2010). No Chile são recomendadas práticas que reduzam a dor e o sofrimento decorrente destes manejos, como o uso da analgesia, a substituição por técnicas não cirúrgicas, a realização destes mais precocemente e a seleção genética para eliminar animais com características que necessitam de procedimentos cirúrgicos (MINISTERIO DE AGRICULTURA, 2012). Recentemente, o Canadá, por meio do Código de Conduta de Práticas e Manejo de Suínos, recomendou que os procedimentos fossem eletivos, sendo executados por pessoas que detenham habilidade para fazê-los, e que sejam elevados nos protocolos os rigores quanto à 
higiene e à manutenção dos equipamentos utilizados nos processos, visando reduzir ao máximo o estresse, a dor e o desconforto do animal (NFACC, 2014).

Segundo Marchant-Forde et al. (2009), para a minimização do estresse inerente aos procedimentos aplicados aos leitões e aos manejos empregados na sua execução, estes devem ser conduzidos por pessoas treinadas e experientes, que ajam com precisão, segurança e rapidez, gerando o mínimo dano aos tecidos.

Na suinocultura industrial brasileira a prática destas mutilações constitui uma rotina. O corte da cauda e dos dentes frequentemente é realizado nas primeiras horas de vida do leitão, como parte de um mesmo conjunto de atividades, e a castração dos machos, uma prática geralmente realizada sem anestesia e/ou analgesia, até a primeira semana de vida (MORES et al., 1998). Este cenário decorre ainda da ausência de uma regulamentação específica sobre estes procedimentos, excetuando a produção orgânica de suínos, que não permite ações que impliquem em mutilações, salvo a castração quando é reconhecidamente necessária (MAPA, 2011).

O objetivo desta revisão é discutir o impacto das práticas de manejo realizadas em leitões lactentes sobre o bem-estar dos animais, analisando sua importância e essencialidade, além de apontar perspectivas para a suinocultura industrial brasileira.

\section{PRÁTICAS DE MANEJO}

\section{Castração}

O principal objetivo da castração dos machos é a prevenção do odor/sabor repulsivo da carne após sua submissão ao tratamento térmico, decorrente principalmente da participação do hormônio androstenona e da substância escatol (RAULT et al., 2011). Há anos, tradicionalmente, a intervenção cirúrgica constitui um dos principais métodos utilizados para a castração, todavia representa uma agressão para o bem-estar do suíno com evidências que quando realizada sem anestesia induz à dor nos leitões (SVC, 1997).

A conduta cirúrgica sem anestesia e analgesia, realizada na primeira semana de vida, induz a dores agudas e crônicas e alterações no comportamento. Após o processo, os leitões 
demonstram reduzidas atividades dirigidas ao úbere (massagens e amamentação) e permanecem mais tempo inativos durante as primeiras duas horas e meia após a castração. Verificou-se também a presença de comportamentos de dor relacionados ao procedimento (prostração, rigidez ao caminhar e tremor) durante as primeiras horas, as quais se estenderam durante dois dias. Nesta sequência, os leitões desenvolveram exercícios de coçar o posterior contra o piso ou a parede, movimentos laterais com a cauda (ambos como resposta à dor devido ao dano local) e permaneceram mais tempo juntos ou amontoados. Alguns destes comportamentos persistiram por até quatros dias após a castração (HAY et al., 2003).

A castração cirúrgica sem anestesia ou analgesia promove uma ativação aguda do sistema nervoso simpático e do eixo hipotálamo-hipófise-adrenal. Prunier et al. (2005) submeteram leitões com 7 a 8 dias de idade ao procedimento e após o manejo observaram significativos aumentos nos níveis do hormônio adrenocorticotrófico (durante 5 a 60 minutos), do cortisol plasmático (durante 15 a 90 minutos) e do lactato (durante 5 a 30 minutos), indicando um severo estado de estresse e um importante dano tecidual. Durante a realização desse procedimento, a vocalização de alta frequência dos leitões (maior que $1000 \mathrm{~Hz}$ ) associa-se com a dor, devendo, portanto, ser utilizada como um indicador do estado de agressão/dor percebida pelo animal. As fases da castração que apresentaram mais alta frequência de vocalização foram durante a incisão da bolsa escrotal com a simultânea externalização dos testículos, durante o tracionamento dos testículos, e durante o corte dos cordões espermáticos (TAYLOR; WEARY, 2000).

A castração, também por motivos operacionais, há muito tempo vem sendo realizada em leitões neonatos, pois se estima que são menos sensíveis à dor do que leitões mais velhos. No entanto, para Taylor et al. (2001), a experiência da dor pela castração não mostrou ser diferente se realizada na 1 a, 2 a ou $3^{\text {a }}$ semana de idade (3, 10 e 17 dias, respectivamente). Os autores verificaram que os leitões mostraram resposta vocal imediata à dor da castração tanto em alta (maior $1000 \mathrm{~Hz}$ ) quanto em baixa frequência (menor $1000 \mathrm{~Hz}$ ), como também no número total de vocalizações. Quanto ao comportamento, independentemente da idade, os leitões castrados permaneceram mais tempo sentados ou em estação e menos tempo 
deitados, quando comparados com leitões não castrados. As taxas de vocalizações de alta frequência foram menores em leitões mais jovens, tendo sido castrados ou não, permitindo concluir que o maior número de vocalizações em animais mais velhos, com mais de uma semana de idade, é consequência do aumento da capacidade de vocalização e não devido à maior sensibilidade à dor, como foi sugerido no passado.

A Declaração Européia sobre as alternativas da castração, assinada em dezembro de 2010, foi um acordo entre os principais atores da cadeia produtiva de suínos visando o abandono voluntário da prática da castração cirúrgica na União Européia até janeiro 2018. O primeiro passo desta ação foi o fim da castração cirúrgica sem analgesia prolongada e/ou anestesia a partir de 1 o de janeiro de 2012. O segundo passo envolveu a ratificação da proibição do procedimento a partir de 1ㅇ de janeiro de 2018 (COMISIÓN EUROPEA, 2010). Com este acordo, a necessidade do desenvolvimento de alternativas para a castração cirúrgica tornouse uma realidade. Neste sentido, a União Européia adotou um programa para financiar estudos sobre o tema, cujos resultados definiram três linhas de ação: o abate de animais jovens (não maduros sexualmente), a castração cirúrgica com anestesia/analgesia e a imunocastração (UNIÓN EUROPEA, 2011).

De acordo com o comitê científico da Autoridade Europeia de Segurança Alimentar (EFSA, 2004), as evidências sugerem que a castração cirúrgica é um ato doloroso em qualquer idade, e a anestesia local com lidocaína intra-testicular e/ou no cordão espermático, com ou sem anestesia subcutânea, é efetiva para reduzir a dor aguda da castração. O comitê sugere que a anestesia local e a analgesia deveriam ser usadas como rotina para a castração de leitões.

No entanto, sob condições comerciais, a utilização em larga escala destas técnicas que minimizam a dor resulta em um manejo adicional com efetividade variável, contrastando com os benefícios gerados para o bem-estar, dificultando a viabilidade do uso rotineiro da anestesia e da analgesia para leitões (VAN BORELL et al., 2009). Além disso, é importante considerar que o uso de analgésicos apresenta um custo adicional para o produtor (RAULT et al., 2011). 
Assim, vários estudos vêm sendo desenvolvidos com o objetivo de aliviar a dor da castração cirúrgica, incluindo o uso de gases inalatórios com propriedades analgésicas de rápida indução, curto período de ação, alta reversibilidade dos efeitos e livres do uso da agulha. $O$ óxido nitroso $\left(\mathrm{N}_{2} \mathrm{O}\right)$ foi avaliado em leitões com três dias de idade (exposição ao gás por 150 segundos antes e durante o procedimento) e demonstrou ser efetivo para induzir a anestesia durante o manejo. Entretanto, o estado de anestesia foi relativamente leve, pois quando foi iniciada a incisão do escroto os leitões acordaram e manifestaram comportamentos de dor, demonstrando que o $\mathrm{N}_{2} \mathrm{O}$ isoladamente tem um insuficiente efeito analgésico no processo (RAULT; LAY, 2011).

O dióxido de carbono $\left(\mathrm{CO}_{2}\right)$, por sua vez, foi utilizado em leitões com menos de oito dias de idade (exposição a $100 \%$ de $\mathrm{CO}_{2}$ por 25 segundos antes do procedimento) e demonstrou ser efetivo para aliviar a dor durante a castração. No entanto, logo após o procedimento os leitões manifestaram comportamento de dor similar aos animais castrados sem anestesia, indicando que o uso do $\mathrm{CO}_{2}$ demanda acompanhamento de uma analgesia adicional para eliminar a dor após a castração (VAN BEIRENDONCK et al., 2011).

A anestesia local demonstrou ser efetiva para reduzir a dor durante a castração (lidocaína administrada na região intratesticular e no escroto, 3 minutos antes do procedimento), e a analgesia com antiinflamatório não esteróide (meloxicam) foi exitosa em reduzir a dor após a castração. Portanto, recomenda-se adotar protocolos de castração utilizando a anestesia local e a analgesia para mitigar a dor aguda e crônica deste procedimento cirúrgico (HANSSON et al., 2011).

Embora seja possível atingir bons resultados com o uso de anestésicos nos estudos experimentais, é necessário mensurar a viabilidade destes métodos nos sistemas de produção, considerando o adicional de trabalho demandado, o tempo para execução do procedimento, a segurança para as equipes envolvidas e os custos inerentes (RAULT; LAY, 2011). O método considerado adequado para o setor produtivo deve ser rápido, rentável, produzir o mínimo estresse e dor durante e após a castração, além de assegurar uma rápida recuperação dos leitões, para minimizar os riscos de morte por esmagamento (HANSSON et al., 2011). 
O abate de suínos inteiros para atender mercados específicos é uma realidade em vários países e regiões. Um estudo com 454 unidades de engorda em empresas espanholas entre 2008 e 2010 identificou que $70 \%$ das granjas que abatem suínos com peso vivo entre $95-110$ kg alojam machos inteiros ao invés de machos castrados, mas nenhuma das granjas que sacrifica animais pesados (120-130 kg) alojou machos inteiros (AGOSTINI et al., 2013). Esta informação comprova que é possível segmentar a cadeia produtiva, mantendo animais inteiros e castrados em um mesmo sistema.

A produção de machos inteiros apresenta ganhos para o bem-estar de animais jovens por evitar a dor e o desconforto da castração cirúrgica, mas este cenário pode ser comprometido pela agressividade e o comportamento de monta, que ganham intensidade e frequência com a evolução da engorda. Os machos inteiros são mais agressivos quando comparados com os machos castrados e as fêmeas, apresentando comportamentos sexuais ainda quando jovens, montando tanto machos quanto fêmeas (EFSA, 2004).

É importante considerar que os desafios do abate de machos inteiros podem ser reduzidos por meio da seleção genética e da modificação da alimentação, visando reduzir a quantidade de androstenona e escatol produzidos (RAULT et al., 2011).

Embora o abate de machos inteiros não seja permitido no Brasil pelo Ministério da Agricultura Pecuária e Abastecimento (MAPA) (BRASIL, 1952), animais com os testículos preservados podem representar futuramente uma alternativa para o país, desde que sejam trabalhadas as questões vinculadas ao hábito e à tradição alimentar do consumidor, que podem ser comprometidas por esta mudança.

A imunização de machos jovens contra o hormônio liberador da gonadotrofina ( $G n R H)$ tem sido considerada uma conduta efetiva, atuando na inibição da função testicular, apresentando vantagens em termos de bem-estar animal, pois elimina os danos do processo cirúrgico (RAULT et al., 2011).

A vacinação contra o GnRH envolve a administração de uma forma modificada do hormônio ou de um análogo conjugado com uma proteína estranha e combinada com um adjuvante para induzir a formação de anticorpos anti-GnRH. A imunização se dá por meio de duas doses com intervalo de 4 a 6 semanas, devendo a última dose ser feita aproximadamente 4 
semanas antes do abate. A redução da concentração de androstenona e do escatol é similar aos níveis observados nos machos castrados cirurgicamente (EINARSSON, 2006).

O abate de suínos imunocastrados, autorizado no Brasil no ano de 2007, é uma técnica em expansão (HECK, 2011a). O MAPA (2007) estabelece que a 2a dose não supere o prazo de 8 semanas até $o$ abate.

Antes de receberam a $2 \underline{a}$ dose da vacina os machos apresentam características e comportamentos de animais não castrados. Após, ganham a condição de castrados, exibindo reduzida agressividade e baixo comportamento de monta. Os riscos da perda do bem-estar, decorrente do manejo da vacinação e do comportamento mais inquieto dos animais durante a fase de engorda antes da aplicação da segunda dose (VAN BORELL et al., 2009), soma-se à pouca qualificação ou capacitação das equipes de vacinação, aos erros de contenção e separação dos animais nas baias durante a imunização e aos riscos da ocorrência de abscessos, como em qualquer outra aplicação injetável (HECK, 2011b).

Com relação às restrições impostas à castração cirúrgica, a legislação européia permite que o procedimento seja realizado por pessoas treinadas e através de meios que não sejam por descolamento dos tecidos. A castração sem anestesia somente pode ser realizada até o 7으 dia de vida dos leitões. Caso a castração seja feita após este período, o procedimento deverá ser conduzido por Médicos Veterinários e com anestesia e analgesia prolongada (EUROPEAN COMMISSION, 2008). A normativa australiana recomenda que quando a castração cirúrgica for necessária, deve ser realizada após o 2ํ dia (com a ordem da mamada já estabelecida) e antes do 70 dia de vida. Quando executada entre o 8 e o 210 dia são necessários apropriados e efetivos meios de contenção. Após o 210 de vida apenas os Médicos Veterinários podem realizá-la, porém sem dispensar o uso de anestesia (PISC, 2008). De acordo com a legislação da Nova Zelândia é desejável que a castração cirúrgica não seja realizada, mas caso seja indicada, deverá ser operacionalizada por Médicos Veterinários, independentemente da idade do suíno (NAWAC, 2010). No Canadá a castração cirúrgica após o 10으 dia de vida deve ser feita com anestesia e analgesia. A partir de julho de 2016 o uso de analgésicos na castração em todas as idades será obrigatório (NFACC, 2014). 


\section{Corte dos dentes}

O corte ou desgaste dos dentes dos leitões constitui uma rotina desenvolvida em muitas propriedades, embora esteja se tornando um procedimento em desuso (AVMA, 2013; WIDOWSKI; TORREY, 2002). Os leitões nascem com quatro dentes incisivos e quatro caninos decíduos eclodidos (SISSON, 1982), cuja função é auxiliar a apreensão do teto durante as mamadas.

O corte dos dentes visa promover inicialmente uma redução nas lesões no úbere da matriz e nos outros leitões em função das disputas pelo acesso aos tetos para mamar. No entanto, esta prática é questionada pelo desconforto causado aos leitões e pelo risco potencial de infecções devido à abertura da cavidade pulpar dos dentes (AVMA, 2013).

Independente da técnica utilizada no manejo, corte dos dentes com o alicate ou o seu desgaste com lixas ou outros instrumentos, a ocorrência de lesões varia desde a abertura e exposição da cavidade pulpar, às hemorragias, infiltrações, abscessos, formação de osteodentina, até a fratura do dente. A maioria destes danos é mais comum e mais precoce quando se faz o uso do alicate no manejo. Considerando as características das lesões, e que se estas estivessem presentes no homem provocariam dor severa, presume-se que o corte dos dentes dos leitões também levaria à mesma sensação dolorosa. Contudo, nos casos em que a prática do corte dos dentes é necessária, deve-se realizá-la através do desgaste, pois as lesões são menos frequentes e menos dolorosas (HAY et al., 2004).

Um estudo realizado com leitões em fase de crescimento/terminação que apresentavam baixo desenvolvimento, embora clinicamente saudáveis, identificou que 10,9\% destes animais apresentavam abscessos dentários, com maior prevalência nos terceiros incisivos e caninos inferiores (NOTTAR, 2007). Outra investigação com leitões na fase de creche que apresentavam atraso no desenvolvimento, compatível com a síndrome multissistêmica do definhamento (SMD), identificou que 20,7\% destes animais apresentavam abscesso dentário, sendo as lesões mais frequentes também nos terceiros incisivos e caninos inferiores (KOLLER et al., 2008). Segundo os autores, a maior prevalência de lesões nestes dentes está provavelmente associada à maior área de corte ou de desgaste a que são submetidos, pois são os dentes mais proeminentes ao nascimento. 
As restrições legais ao corte dos dentes dos leitões são inúmeras. A normativa europeia permite a redução uniforme das pontas dos dentes dos leitões somente até o 700 dia de vida, mediante desgaste ou corte parcial, deixando, todavia, sua superfície lisa e intacta (EUROPEAN COMMISSION, 2008). A Austrália limita a remoção à quarta parte da coroa do dente, devendo o procedimento ser executado nos três primeiros dias de vida (PISC, 2008). A Nova Zelândia admite o corte dos dentes antes do 5ㅇ dia de vida, e recomenda o desgaste em detrimento do corte (NAWAC, 2010). O Canadá recomenda que apenas os leitões que demonstram comportamentos agressivos com seus irmãos de leitegada ou com as amas de leite devam ter seus dentes cortados, limitando a remoção entre um terço e a metade da coroa (NFACC, 2014).

Paralelamente, tem sido defendido que esta prática pode ser eliminada sem transtornos quando se trabalha com linhas genéticas mais calmas ou quando são evitadas leitegadas numerosas durante a amamentação (AVMA, 2013). Portanto, a rotina do corte dos dentes precisa ser objetivamente avaliada, considerando as hipotéticas vantagens (menos danos nas leitegadas e nos úberes das fêmeas) e as reais desvantagens (dor e desordens na saúde e no desempenho dos leitões).

\section{Corte da cauda}

Muitos produtores amputam parcialmente a cauda dos leitões recém-nascidos como uma medida prática para controlar a caudofagia, um comportamento anormal no crescimento/terminação com repercussões econômicas e de bem-estar negativas. A caudofagia ocorre em dois estágios: um primeiro sem lesões; já o segundo com sangramentos e infecções que podem conduzir o animal à morte. Caso o animal sobreviva, podem ocorrer prejuízos significativos decorrentes destas lesões no abate, com perdas parciais ou totais da carcaça (WIDOWSKI; TORREY, 2002).

O corte da cauda tradicionalmente era realizado com alicate, gerando uma secção abrupta. Atualmente este instrumento ainda persiste em muitas granjas, mas também se faz uso de equipamentos com lâminas aquecidas que simultaneamente executam a secção da cauda e cauterizam a ferida, o que confere ganhos ao bem-estar pela redução dos riscos de 
infecções. Todavia, deve-se atentar para o risco de contatos acidentais com a cauda ou outras partem com o equipamento aquecido, podendo ocasionar queimaduras superficiais (MARCHANT-FORDE et al., 2009).

Uma estratégia para mitigar a dor após o corte da cauda envolve o uso tópico de anestésicos diretamente no local. O spray de lidocaína associada com iodo povidine mostrou reduzir os comportamentos associados à dor, diminuindo também o sangramento e acelerando a cicatrização. Leitões submetidos a essa prática de manejo e que não receberam este tratamento subseqüente, apresentaram maiores taxas de infecções e abscessos, e tiveram uma cicatrização mais lenta da ferida (STROBEL; HAWKINS, 2012).

Independentemente do método utilizado para o corte da cauda, a ação é estressante e resulta em dor aguda (NANNONI et al., 2014), embora geralmente estas respostas sejam menos intensas em relação à castração cirúrgica (PRUNIER et al., 2005). O corte da cauda também pode ter consequências negativas extensivas ao bem-estar, como a dor crônica e o estresse, limitando a capacidade de comunicação do leitão, que redireciona o comportamento da mordida para outras partes do corpo dos companheiros de baia, como orelhas e pernas (NANNONI et al., 2014).

A eficácia do corte da cauda para reduzir a frequência da caudofagia é difícil de ser estimada, pois depende do nível da caudofagia no grupo controle (suínos que não foram submetidos ao corte de cauda). Em condições de criação intensiva, o corte da cauda reduz a frequência da caudofagia, mas não elimina completamente o problema quando as condições desfavoráveis persistem (EFSA, 2007).

Um estudo histopatológico demonstrou que na extremidade da cauda há uma inervação periférica responsável pela sua sensibilidade local, sendo um erro assumir que a cauda intacta é insensível. Além disso, caudas amputadas podem se tornar altamente sensitivas devido à formação de neuromas, estruturas descritas como causadores de dores crônicas em membros humanos amputados (SIMONSEN et al., 1991). A formação de neuromas e o nível de dor crescem à medida que se aumenta a extensão amputada. Suínos com 75, 50 e $25 \%$ da cauda removida apresentaram, respectivamente, 100, 79 e $41 \%$ de neuromas (HERSKIN et al., 2010). Embora o corte da cauda constitua um procedimento ainda bastante 
utilizado, a cauterização com ferro quente causa mais distresse e formação de neuromas (AVMA, 2013).

A caudofagia é considerada um comportamento anormal de origem multifatorial. Os surtos são imprevisíveis nas granjas e de difícil reprodução experimental (MOINARD et al., 2003). O problema raramente é descrito em produções de suínos extensivas, semi extensivas ou em criações de javalis, mas é frequente em sistemas onde o comportamento natural é restringido, como no sistema intensivo. A prevalência de caudofagia na fase de crescimento foi avaliada em cinco diferentes sistemas de produção. No sistema convencional a taxa foi de 2,5\%, no sistema de cama sobreposta, 1,4\%; já nas criações intensivas de suínos ibéricos os valores foram de $0,1 \%$; enquanto não foi registrado nenhum caso nos dois sistemas extensivos avaliados (criação do suíno ibérico e do black Mallorcan pig) (TEMPLE et al., 2012).

As hipóteses sobre as origens da caudofagia sugerem que sua ocorrência se deve ao comportamento exploratório redirigido, sendo decorrente do "tédio" que os animais criados intensivamente sofrem. Também sua presença está associada à oferta de dietas desequilibradas, com falta de sal ou de fibra; ou à práticas inadequadas de manejo, como temperatura e ventilação ambiental fora das demandas exigidas pela categoria, altos níveis de amônia etc. (MOINARD et al., 2000). No entanto, a limitação da exploração do ambiente, como um comportamento alimentar próprio da espécie, é considerada como o principal fator motivador da caudofagia (EFSA, 2007).

Os fatores de risco para a caudofagia, segundo um estudo de caso realizado em 92 granjas da Inglaterra, indicaram que a adição de palha para os animais, uma ou mais vezes ao dia, reduziu em 10 vezes o risco do problema; que os pisos ripados ou parcialmente ripados, versus os pisos compactos, aumentaram o risco do problema em 3,2 vezes; que os sistemas de alimentação com cinco ou mais suínos por espaço no comedouro aumentaram o risco em 2,7 vezes; que densidades iguais ou superiores a $110 \mathrm{~kg}$ de suínos $/ \mathrm{m}^{2}$ aumentaram o risco da caudofagia em 2,7 vezes; que granjas que pertenciam a empresas que gerenciavam cinco ou mais unidades de produção tinham o risco aumentado em 3,5 vezes; e que o aumento do 
número de baias por trabalhador também aumentava o risco em 1,06 vezes (MOINARD et al., 2003).

A gravidade das lesões de caudofagia não é afetada pelo tamanho do grupo de animais nas baias de crescimento/terminação (grupos com 10, 20, 40 e 80 suínos/baia), mas a incidência do problema aumenta com o avanço da idade dos suínos (SCHMOLKE et al., 2003). No sistema convencional a estimativa de risco de ocorrência de caudofagia foi cinco vezes maior na metade da fase de crescimento (quando os suínos tinham 107 dias de idade) do que na fase inicial (quando os suínos tinham menos de 90 dias); nas granjas que adotaram o sistema de alimentação líquida (in-trough) o problema esteve mais presente em relação aos modelos que utilizavam ração úmida (wet-feed hopper); como também sob condições de baixas temperaturas (média $20^{\circ} \mathrm{C}$ ), comparadas com altas temperaturas ambientais (média $26^{\circ} \mathrm{C}$ ). De acordo com o estudo, a idade do suíno representou um fator relevante, devendo ser levado em consideração quando são avaliadas as ocorrências de caudofagia, assim como a duração da restrição alimentar, que pode provocar frustrações e distúrbios nos grupos; e o aumento das atividades dos animais em ambientes com temperaturas mais baixas, que pode elevar o risco de incidência do problema (TEMPLE et al., 2012).

Para prevenir a caudofagia algumas medidas podem ser tomadas, como prover palha fresca diariamente aos animais (esta medida é válida desde o nascimento até a engorda), manter a densidade animal abaixo de $110 \mathrm{~kg} / \mathrm{m}^{2}$ e oferecer espaço nos comedouros para que mais de 20\% dos suínos se alimentem ao mesmo tempo (MOINARD et al., 2003).

O corte da cauda como prevenção à caudofagia tem uma eficácia menor em relação ao que é prescrito e esperado. O melhor método para preveni-la se dá pela eliminação dos fatores ambientais que são responsáveis pelo seu surgimento, ao invés da amputação cirúrgica sistemática da cauda. Os problemas de caudofagia devem ser resolvidos por meio de uma melhor gestão e não pelo corte da cauda (SVC, 1997).

Do ponto de vista legal, as normativas têm restringido essa prática rotineira de manejo. A legislação europeia proíbe o uso regular desta medida, permitindo o corte parcial da cauda sem anestesia caso este venha a ser realizado até o 70 dia de vida. A partir desta idade o procedimento pode ser feito somente com anestesia e analgesia prolongada, e por Médicos 
Veterinários (EUROPEAN COMMISSION, 2008). A Austrália também recomenda evitar o corte da cauda, mas quando realizado, deve ser antes do 70 dia de vida (PISC, 2008). A Nova Zelândia orienta que, quando necessário, o manejo seja realizado até o 3o dia de vida (72 horas), limitando a mutilação entre um terço e a metade da cauda. E caso o corte seja realizado após o 7ํ dia de vida, somente Médicos Veterinários podem executá-lo (NAWAC, 2010). As normas canadenses orientam que diante da necessidade de execução do manejo, que este seja feito entre 24 e 72 horas de vida, seccionando uma porção mínima que preserve a cobertura do ânus pela porção da cauda remanescente. O corte da cauda após o 70 dia deve ser realizado com o controle efetivo da dor. Porém, a nova orientação trata que a partir de julho de 2016 o uso de analgésicos no protocolo de corte da cauda será obrigatório para suínos de todas as idades (NFACC, 2014).

O corte da cauda é uma medida adequada para prevenir os sintomas e o comportamento da caudofagia, comuns em suínos criados intensivamente, mas não soluciona as causas deste problema (SONODA et al., 2013). Portanto, a caudofagia poderia ser considerada um indicador de um ambiente inadequado, sendo o comportamento um fomentador para as melhorias das condições de alojamento, com a implementação de estratégias de enriquecimento ambiental antes da adoção rotineira desse tipo de manejo (NANNONI et al., 2014).

\section{Procedimentos para identificar os animais}

Para garantir a rastreabilidade e permitir um apropriado controle nas granjas, os suínos, em especial aqueles destinados à reprodução, necessitam ser identificados individualmente (MADEC et al., 2001). No entanto, de forma semelhante à castração, ao corte de cauda e ao corte dos dentes, os procedimentos de identificação causam comprometimento do bemestar, variando com o protocolo utilizado e a amplitude da mutilação causada. A identificação comumente é feita nas orelhas por meio da mossagem e perfuração, da colocação de brincos e da tatuagem. No corpo do suíno a tatuagem e a implantação de microchips são os procedimentos adotados de identificação. 
A identificação dos animais através de mossas na orelha ou marcação australiana é um procedimento permanente e de baixo custo. Os brincos apresentam o inconveniente da perda acidental ou da extração proposital (WIDOWSKI; TORREY, 2002). Todavia, a mossagem vem sendo substituída pelos brincos, pois requer mais mão de obra e tempo para ser efetuada e ainda apresenta mais dificuldade para leitura, muito embora ainda venha sendo utilizada em granjas comerciais, principalmente em granjas de melhoramento genético (AVMA, 2013).

Quanto ao bem-estar dos leitões, a colocação de brincos é menos invasiva, sendo, portanto, melhor pelo menor dano tecidual. Leitões mossados, por sua vez, demonstram uma tendência de elevação da taxa de cortisol plasmático ( 4 horas após o procedimento) e apresentam feridas mais severas que demoram mais tempo para cicatrizar ( 1 e 2 semanas após o procedimento), quando comparadas com as lesões oriundas da colocação dos brincos (MARCHANDT-FORDE et al., 2009).

O uso de brincos e a tatuagem são os métodos tradicionais mais utilizados (MADEC et al., 2001). A tatuagem é uma técnica que conduz ao menor estresse quando realizada com equipamentos adequados e por pessoal habilitado (AVMA, 2013).

A identificação através da mossagem ou da colocação de brincos pode naturalmente causar dor e vir a representar um problema mais sério de bem-estar, principalmente se for realizada de forma inadequada. No caso mais polêmico e em desuso, a mossagem, com a retirada (mutilação) de um segmento da orelha, provoca dor no animal proporcional à superfície da área seccionada (SVC, 1997).

Com relação às orientações e restrições legais a estas práticas, existem diferenças entre os países. A legislação europeia não proíbe ou restringe estes procedimentos (EUROPEAN COMMISSION, 2008). No entanto, a normativa australiana recomenda evitar o uso da mossa, mas quando realizada deve ser feita antes do 70 dia de vida (PISC, 2008). Na Nova Zelândia a mossagem pode ser realizada até o 3 dia de vida (NAWAC, 2010). No Canadá a mossa deve ser feita, quando necessária, até o 14으 dia de vida, no máximo. O país também recomenda o uso de analgésicos nos protocolos de tatuagem e mossagem, evitando que os 
procedimentos sejam feitos próximos dos principais vasos sanguíneos e da parte superior da cartilagem da orelha (NFACC, 2014).

Neste sentido, as identificações devem ser minimamente invasivas, causando reduzidos danos aos tecidos envolvidos e, consequentemente, com menor impacto no bem-estar dos animais.

\section{CONCLUSÃO}

As práticas da castração, corte da cauda, corte dos dentes e identificação são dolorosas e afetam o bem-estar dos leitões independentemente de sua idade.

As rotinas do corte da cauda e corte dos dentes mostram-se desnecessárias quando os suínos estão atendidos em suas necessidades básicas, sendo que nestas condições a eliminação profilática das mesmas não causa prejuízos.

A anestesia e analgesia prolongada devem estar presentes nos protocolos de castração, corte da cauda e identificação, como medidas para minimizar os seus impactos negativos no bem-estar animal.

A imunocastração ou o abate de machos jovens são alternativas para substituir a castração cirúrgica, pois trazem benefícios para o bem-estar animal.

\section{MANAGEMENT PRACTICES WITH SUCKLING PIGLETS: REVIEW AND PERSPECTIVES RELATED TO ANIMAL WELFARE}

\section{ABSTRACT}

T he procedures of male castration, tail section, cut or wear of teeth and identification of piglets are largely performed after birth in commercial farms. Despite of the clear goals of these practices they result in acute and chronic pain in piglets, representing a major welfare problem. The social pressure to ban these procedures has been intensified, and several countries are restricting the routine use of these practices through normativenesses. Currently it has been questioned how much and what is the need to maintain these practices, particularly in Brazil that still demands legislation on this subject. This review examines the impact of these procedures on the welfare of pigs and the 
perspectives for the Brazilian productive sector to adapt itself to these new trends. In summary we can assume that cutting the tail and the teeth are two technically unnecessary routines when pigs have their basic needs met. When the castration is maintained it shall be performed with the use of anesthesia and prolonged analgesia. Another option is the immunocastration. Considering all procedures, it is possible to apply some practices to minimize the inherent negative impacts of them, especially through a constant training of people, use of proper equipments and the hygiene maintenance in these managements.

Keywords: Directives. Identification of pigs. Surgical castration. Tail docking. Teeth clipping.

\section{PRÁCTICAS DE MANEJO CON LECHONES LACTENTES: REVISIÓN Y PERSPECTIVAS VINCULADOS AL BIENESTAR DE LOS ANIMALES}

\section{RESUMEN}

os procedimientos de castración de los machos, la sección de la cola, el corte o desgaste de los dientes y la identificación de los lechones son prácticas ampliamente realizadas después del nacimiento en explotaciones comerciales. Aunque estas acciones tengan propósitos claramente definidos, se traducen en dolor agudo y crónico en los lechones, lo que representa un importante problema de bienestar. La presión social para prohibir estos procedimientos se ha intensificado y varios países han restringido el uso rutinario de estas prácticas a través de las normativas. Actualmente es cuestionable la forma y la necesidad de mantener estas prácticas, sobre todo en Brasil, que aun no tiene una legislación sobre el tema. Esta revisión examina el impacto de estos procedimientos en el bienestar de los cerdos y las perspectivas para el sector productivo brasileño en la adaptación a estas nuevas tendencias. En resumen, se puede atribuir que técnicamente las rutinas de amputación de la cola y recorte de los dientes aparecen técnicamente no necesarias cuando los cerdos tienen sus necesidades básicas satisfechas. La castración, si mantenida, se efectuará mediante el uso de anestesia y analgesia prolongada. Otra opción es la inmunocastración. Para todas las prácticas hay que mirar en la posibilidad de minimizar los impactos negativos inherentes a través de la capacitación constante de la mano de obra, el uso adecuado de los equipos y el mantenimiento de la higiene en estas prácticas.

Palabras clave: Castración quirúrgica. Sección de cola. Corte de dientes. Identificación de los cerdos. Normativa. 


\section{REFERÊNCIAS}

AGOSTINI, P. S.; GASA, J.; MANZANILLA, E. G.; et al. Descriptive study of production factors affecting performance traits in growing-finishing pigs in Spain. Spanish Journal of Agricultural Research, v. 11, n. 2, p. 371-381, 2013.

AVMA-AMERICAN VETERINARY MEDICAL ASSOCIATION. Literature review on the welfare implications of teeth clipping, tail docking and permanent identification of Piglets. Disponível em: https://www.avma.org/KB/Resources/ LiteratureReviews/ Pages/Welfareimplications-of-practices-performed-on-piglets.aspx. Acesso em: 12 jul. 2013.

BRASIL. Decreto no 30.691, de 29 de março de 1952. Aprova o novo Regulamento da Inspeção Industrial e Sanitária de Produtos de Origem Animal. In: Diário Oficial da União, Rio de Janeiro, v. 91, n. 155, seção 1, p. 1, 1952.

COMISIÓN EUROPEA. Declaración europea sobre alternativas a la castración quirúrgica de los cerdos. Bruselas. 3p. 2010.

EFSA. Opinion of the Scientific Panel on Animal Health and Welfare on a request from the Commission related to welfare aspects of the castration of piglets. The EFSA Journal, v. 91, p. 1-18, 2004. 100p.

EFSA. Scientific Opinion of the Panel on Animal Health and Welfare on a request from Commission on the risks associated with tail biting in pigs and possible means to reduce the need for tail docking considering the different housing and husbandry systems. The EFSA Journal, v. 611, n. 1-13, 2007. 109p.

EINARSSON, S. Vaccination against GnRH: pros and cons. Acta Veterinaria Scandinavica, v. 48, n. 10, p. 4, 2006.

EUROPEAN COMMISSION. Council Directive 2008/120/EC of 18 December 2008 laying down mínimum standards for the protection of pigs (Codified version). Official Journal of the European Union, NL 47, p. 5, 18 fev. 2009.

FAWC-FARM ANIMAL WELFARE COUNCIL. Updates the five freedoms. Veterinary Records, v. 131, n. 17, p. 357, 1992.

HANSSON, M.; LUNDEHEIM, N.; NYMAN, G.; et al. Effect of local anaesthesia and/or analgesia on pain responses induced by piglet castration. Acta Veterinaria Scandinavica, v. 53, p. 34, 2011.

HAY, M.; VULIN, A.; GÉNIN, S.; et al. Assessment of pain induced by castration in piglets: behavioral and physiological responses over the subsequent 5 days. Applied Animal Behaviour Science, v. 82, p. 201-218, 2003. 
HAY, M.; RUE, J.; SANSAC, C.; et al. Long-term detrimental effects of tooth clipping or grinding in piglets: a histological approach. Animal Welfare, v. 13, p. 27-32, 2004.

HECK, A. A revolution in pork production. In: LONDON SWINE CONFERENCE - EXPLORING THE FUTURE, 11, 2011, Ontario. Proceedings. Ontario, p. 19-26, 2011a.

HECK, A. Imunocastration in swine: a practical approach. In: LONDON SWINE CONFERENCE EXPLORING THE FUTURE, 11, 2011, Ontario. Proceedings. Ontario, p. 135-142, $2011 \mathrm{~b}$.

HERSKIN, M. S.; HOLM, B.; WAAG, R.; et al. Effects of pig tail docking and docking length on the formation of neuromas. In: BENZON SYMPOSIUM ACUTE PAIN - PATHOPHYSIOLOGY AND RISK FACTORS FOR CHRONIFICATION, 57, 2010, Copenhagen. Proceedings. Copenhagen, 2010. p. 9.

KOLLER, F. L.; BOROWSKI, S. M.; ASANOME, W.; et al. Abscessos dentários periapicais em leitões com síndrome multissistêmica do definhamento. Pesquisa Veterinária Brasileira, $v$. 28, p. 271-274, 2008.

MADEC, F.; GEERS, R.; VESSEUR, P.; et al. Traceability in the pig production chain. Revue Scientifique et Technique, v. 20, n. 2, p. 523-537, 2001.

MAPA-MINISTÉRIO DA AGRICULTURA PECUÁRIA E ABASTECIMENTO. Ofício circular no 001/2007/DICS/CGI/DIPOA. Autorização para o abate de suínos imunocastrados por meio de vacina. Brasília, 2007. 4p.

MAPA-MINISTÉRIO DA AGRICULTURA PECUÁRIA E ABASTECIMENTO. Instrução normativa no 46, de 6 de outubro de 2011. Estabelece o regulamento técnico para os sistemas orgânicos de produção animal e vegetal. Diário Oficial da União, Brasília, n. 194, seção 1, p. 4, 7 de out. 2011.

MARCHANT-FORDE, J. N.; LAY, D. C. Jr.; Mc MUMM, K. A.; et al. Postnatal piglet husbandry practices and well-being: the effects of alternative techniques delivered separately. Journal of Animal Science, v. 87, p. 1479-1492, 2009.

MINISTERIO DE AGRICULTURA. Decreto no 29 de 5 de junio de 2012. Aprueba reglamento sobre protección de los animales durante su producción industrial, su comercialización y en otros recintos de mantención de animales. Santiago, Biblioteca del Congresso Nacional de Chile, 24 de mayo 2013.

MOINARD, C.; MENDL, M.; NICOL, C. J.; et al. Investigations into risk factors for tail-biting in pigs on commercial farms in England, UK. In: INTERNATIONAL SYMPOSIUM ON VETERINARY EPIDEMIOLOGY AND ECONOMICS, 9, 2000, Colorado. Proceedings. Colorado, 2000.

MOINARD, C.; MENDL, M.; NICOL, C. J.; et al. A case control study of on-farm risk factors for tail biting in pigs. Applied Animal Behaviour Science, v. 81, p. 333-355, 2003. 
MORES, N.; SOBESTIANSKY, J.; WENTZ, I.; et al. Manejo do leitão desde o nascimento até o abate. In: SOBESTIANSKY, J.; WENTZ, I.; SILVEIRA, P. R. S.; SESTI, L. A. C. Suinocultura intensiva: produção, manejo e saúde do rebanho. Concórdia: Embrapa-CNPSa, p. 135-162, 1998.

NANNONI, E.; VALSAMI, T.; SARDI, L.; et al. Tail docking in pigs: a review on its short and long-term consequences and effectiveness in preventing tail biting. Italian Journal of Animal Science, v. 13, p. 98-106, 2014.

NAWAC-NATIONAL ANIMAL WELFARE ADVISORY COMMITTEE. Animal welfare (pigs) code of welfare 2010. New Zealand: MAF Biosecurity, 2010.

NFACC-NATIONAL FARM ANIMAL CARE COUNCIL. Code of practice for the care and handling of pigs. Ottawa, 2014.

NOTTAR, E. Avaliação de causas de baixo desenvolvimento em suínos nas fases de recria e terminação. Porto Alegre: UFRGS, 2007. 52p. Dissertação (Mestrado em Sanidade Suína), Universidade Federal do Rio Grande do Sul, 2007.

PISC-PRIMARY INDUSTRIES STANDING COMMITTEE. Model code of practice for the welfare of animals: pigs. 3. ed. Victoria: CSIRO Publishing, 2008.

PRUNIER, A.; MOUNIER, A. M.; HAY, M. Effects of castration, tooth resection, or tail docking on plasma metabolites and stress hormones in young pigs. Journal of Animal Science, v. 83, p. 216-222, 2005.

RAULT, J. L.; LAY, D. C. Jr. Nitrous oxide by itself is insufficient to relieve pain due to castration in piglets. Journal of Animal Science, v. 89, p. 3318-3325, 2011.

RAULT, J. L.; LAY, D. C. Jr.; MARCHANT-FORDE, J. N. Castration induced pain in pigs and other livestock. Applied Animal Behaviour Science, v. 135, p. 214-225, 2011.

SCHMOLKE, S. A.; LI, Y. Z.; GONYOU, H. W. Effect of group size on performance of growingfinishing pigs. Journal of Animal Science, v. 81, p. 874-878, 2003.

SIMONSEN, H. B.; KLINKEN, L.; BINDSEIL, E. Histopathology of intact and docked pigtails. British Veterinary Journal, v. 147, p. 407-412, 1991.

SISSON, S. Sistema digestivo de los porcinos. In: SISSON, S.; GROSSMAN, J. D. Anatomía de los animales domésticos. 5. ed. Barcelona: Salvat, 1982. Cap. 40, p. 1398-1413.

SONODA, L. T.; FELS, M.; OCZAK, M.; et al. Tail biting in pigs--causes and management intervention strategies to reduce the behavioural disorder. A review. Berl Munch Tierarztl Wochenschr, v. 126, p. 104-112, 2013. 
STROBEL, M.; HAWKINS, P. A. The effect of topical anti-infective application at castration and tail docking of baby pigs versus doing nothing. In NATIONAL ANNUAL MEET, 43, 2012, Denver. Proceeding. Denver: AASV, 2012. p. 247-250.

SVC. Report of the Scientific Veterinary Committee. The welfare of intensively kept pigs. Halle, Doc XXIV/B3/ScVC/0005, 1997.

TAYLOR, A. A.; WEARY, D. M. Vocal responses of piglets to castration: identifying procedural sources of pain. Applied Animal Behaviour Science, v. 70, p. 17-26, 2000.

TAYLOR, A. A.; WEARY, D. M.; LESSARD, M.; et al. Behavioural responses of piglets to castration: the effect of piglet age. Applied Animal Behaviour Science, v. 73, p. 35-45, 2001.

TEMPLE, D.; COURBOULAY, V.; VELARDE, A.; et al. The welfare of growing pigs in five different production systems in France and Spain: assessment of health. Animal Welfare, $v$. 21, p. 257-271, 2012.

UNIÓN EUROPEA. Decisión de ejecución de la comisión de 19 de agosto de 2011 por la que se adopta un programa de trabajo para la financiación de las actividades de la Unión sobre alternativas a la castración quirúrgica de los cerdos. Comunicaciones e informaciones 2011/C 243/06. Diario Oficial de la Unión Europea, Bruselas, 2011.

VAN BEIRENDONCK, S.; DRIESSEN, B.; VERBEKE, G.; et al. Behavior of piglets after castration with or without carbon dioxide anestesia. Journal of Animal Science, v. 89, p. 3310-3317, 2011.

VAN BORELL, E.; BAUMGARTNER, J.; GIERSING, M.; et al. Animal welfare implications of surgical castration and its alternatives in pigs. Animal, v. 3, n. 11, p. 1488-1496, 2009.

WIDOWSKI, T.; TORREY, S. Neonatal management practices. Fact Sheet, v. 1, n. 6, p. 1-4, 2002. 